A R T I G O S

\title{
COMO INSPIRADO DEL ESPÍRITU SANTO: VASCO DE QUIROGA, PRIMEIRO INTÉRPRETE
} AMERICANO DA UTOPIA

Como inspirado del Espíritu Santo: Vasco de Quiroga, first American interpreter of Utopia

Como inspirado del Espíritu Santo: Vasco de Quiroga, primer intérprete americano de la Utopía

GERALDO WITEZE JUNIOR

http://dx.doi.org/10.1590/S2178-14942017000300002

Geraldo Witeze Junior é mestre em Teoria e História Literária pela Universidade Estadual de Campinas (Unicamp), doutor em História pela Universidade Federal de Goiás (UFG) e professor do Instituto Federal de Educação, Ciência e Tecnologia de Goiás (IFG), campus Formosa. Este artigo recebeu apoio do Programa Institucional de Qualificação de Servidores (PIQ) do IFG (woitze@gmail.com).

Artigo recebido em 28 de maio e aprovado para publicação em 30 de agosto de 2017. 


\title{
RESUMO
}

Este artigo apresenta a interpretação da Utopia de Thomas Morus feita por Vasco de Quiroga em seu tratado intitulado Información en derecho (1535). Quiroga lutou contra a escravidão e propôs a criação de povoados inspirados na obra de Morus como solução para os problemas da colonização espanhola na América. Seus objetivos eram garantir uma vida digna para os indígenas e evangelizá-los sem uso de força, a partir do bom exemplo. Os métodos empregados são oriundos da crítica literária, especialmente a filologia, bem como da exegese textual. A utopia é entendida como projeto político-social concreto e não como mera literatura ou crítica social.

PalaVras-CHAVE: utopia; América; colonização; Vasco de Quiroga (1478?-1565).

\begin{abstract}
This paper presents the interpretation of Thomas More's Utopia written by Vasco de Quiroga in his treatise entitled Información en derecho (1535). Quiroga fought against slavery and proposed the creation of villages inspired by More's work as a solution to the problems of Spanish colonization in America. His objectives were to guarantee a dignified life for the natives and to evangelize them without using force, from the good example. The methods used come from literary criticism, especially philology, as well as textual exegesis. Utopia is understood as a concrete social-political project and not as mere literature or social criticism.
\end{abstract}

KeYwords: utopia; America; colonization; Vasco de Quiroga (1478?-1565).

\section{RESUMEN}

Este artículo presenta la interpretación de la Utopía de Tomás Moro hecha por Vasco de Quiroga en su tratado intitulado Información en derecho (1535). Quiroga luchó contra la esclavitud y propuso la creación de pueblos inspirados en la obra de Moro como solución a los problemas de la colonización española en América. Sus objetivos eran garantizar una vida digna para los indígenas y evangelizarlos sin uso de fuerza, a partir del buen ejemplo. Los métodos empleados proceden de la crítica literaria, especialmente la filología, así como la exégesis textual. La utopía es entendida como proyecto político-social concreto y no como mera literatura o crítica social.

Palabras-ClaVe: utopía; América; colonización; Vasco de Quiroga (1478?-1565). 
asco de Quiroga nasceu em Madrigal de las Altas Torres, Espanha, provavelmente no ano de 1478. Apesar de haver muitas lacunas em sua biografia, é sabido que se licenciou em direito canônico e ocupou postos importantes na administração espanhola entre 1525 e 1530. Neste ano foi escolhido para ocupar o cargo de ouvidor na Segunda Audiência da Nova Espanha, o mais alto órgão de governo daqueles domínios espanhóis, tendo assumido em 1531. Além de ser um órgão executivo, a Audiência exercia a função de suprema corte, o que permitiu a Quiroga ter contato com as narrativas indígenas sobre os males provocados pelos espanhóis (Warren, 1963).

Ao conhecer de perto os problemas apresentados pelos nativos o ouvidor passou a buscar soluções. Suas primeiras ideias ficaram registradas numa carta que escreveu ao ConseIho de Índias ainda em seu primeiro ano no Novo Mundo (Witeze Junior, 2016) e gravitavam em torno do projeto de agrupar os índios em povoados onde pudessem viver com um mínimo de dignidade. Por essa época o bispo de México-Tenochtitlán, Juan de Zumárraga, emprestou- Ihe a Utopia, de Thomas Morus, e a leitura da obra provocou uma reação entusiasmada: ali estava o remédio para o Novo Mundo! Os povoados de índios, chamados de pueblos-hospitales, deveriam seguir o modelo de sociedade descrito na obra do humanista inglês e constituiriam o paradigma da colonização espanhola.

Na década de 1530 Quiroga fundou dois desses povoados: um em Michoacán, a oeste de Tenochtitlán, região habitada pelos Tarascos (ou Purépecha), que não foram subjugados pelos mexicas; outro nos arredores da cidade do México. Pelo resto de sua vida se dedicou à preservação e à consolidação dessa obra, especialmente depois que foi nomeado primeiro bispo de Michoacán, função que exerceu até a sua morte, em 1565. É verdade que o projeto de converter os hospitales no padrão da colonização fracassou, mas esses dois povoados resistiram até a década de 1870, quando finalmente ruíram sob a égide das reformas liberais.

De qualquer forma, é importante conhecê-los para compreender o momento inicial da colonização da Nova Espanha, com sua complexidade polifônica. A linha a ser seguida ainda estava em disputa, ou seja, a tragédia que hoje conhecemos não representava então um movimento inexorável e havia muitos projetos alternativos - entre os quais se contam os povoados utópicos de Quiroga. Ademais, merece destaque a inspiração em uma obra publicada 
pouco antes e a convicção de que a utopia era viável no Novo Mundo. Contrariava, assim, o pessimismo dos humanistas europeus, que viam ruir a cada dia o sonho de que uma sociedade justa e letrada fosse construída no Velho Mundo - a morte de Morus em 1535 e a perseguição a Erasmo são marcos do ocaso dos humanistas (Bataillon, 1966; Green, 1969). Na América, empolgado pela Utopia e por aqueles homens novos, os índios, era possível sonhar e realizar o que na Europa, corrupta e decadente, se tornara impraticável.

Vasco de Quiroga ponderou muito sobre os bons atributos dos índios da Nova Espanha e escreveu longamente sobre isso na Información en derecho - um tratado contra a permissão da escravização dos indígenas, concedida pela coroa em 1534. É na Información que encontramos a descrição do projeto utópico de Quiroga para o Novo Mundo. Ali ele considerava que os indígenas eram propensos à conversão e à implementação de uma boa política e que isso era "un gran milagro y misterio". Tinha então plena confiança na efetivação do seu projeto, pois a mão de Deus o favorecia: " esto, que en nosotros con mucha razón verse hecho se desconfiaría, con mucha mayor en estos naturales se podría tener y contar ya por cosa hecha (por tan hecha y por tan sin duda para mí lo tengo)" (Quiroga, 2002: 195).

A experiência tinha um papel central na visão quiroguiana, permitindo a substituição do pessimismo - originado da notável corrupção da cristandade europeia - pelo otimismo decorrente do conhecimento das muitas qualidades dos índios. Daí que tenha se referido à Utopia desta maneira:

Y ésta pienso haber sido la causa e intención del autor, no de menospreciar, que ordenó y compuso el muy buen estado y manera de república de que se sacó la de mi parecer en ponerla, contarla y afirmarla por cosa vista y hecha y experimentada, y porque, si esto una vez no se experimentase, parece que no se podría creer; pero quien lo tiene experimentado ninguna duda pone en ello. (Quiroga, 2002: 195-196).

O propósito crítico da obra é posto em segundo plano, de modo que o destaque recai sobre o segundo livro, onde se descreve o modo de vida dos utopianos. A intenção não seria menosprezar ${ }^{1}$ a sociedade europeia, mas fazer proposições para sua renovação. Ao evidenciar a dimensão projetiva, entende-se a condenação da sociedade europeia, contida no primeiro livro, menos como uma rejeição escapista e mais como um primeiro passo necessário para a reforma sociopolítica desejada.

\footnotetext{
${ }^{1}$ Diferia, então, do que fez mais tarde Antonio de Guevara em seu Menosprecio de corte y elogio de aldea (1539), talvez porque por essa época o entusiasmo já começasse a arrefecer.
} 
A composição da Utopia é vinculada à experiência do Novo Mundo, que Morus conhecia através das cartas de Américo Vespúcio. ${ }^{2}$ A descrição contida no segundo livro demonstraria a viabilidade da melhor forma de governo, algo muito difícil de crer na velha Europa corrompida. As sociedades indígenas, semelhantes àquelas da Idade do Ouro, por outro lado, permitiam que o desejo expresso pelo Morus-personagem no fim do livro se concretizasse. ${ }^{3}$ A experiência exitosa transformava a mente, fornecendo evidências para dirimir as dúvidas e fortalecer a fé na renovação da humanidade.

Sem ver era difícil crer, mas, tendo visto, não havia espaço para dúvidas. A estrutura narrativa remete ao famoso episódio em que o apóstolo Tomé duvida da ressurreição do Cristo, exigindo ver para crer. ${ }^{4} 0$ modo de vida dos índios, sua bondade e abertura para 0 evangelho eram como as feridas nas mãos de Jesus em que Tomé pôs as mãos: quem quisesse podia verificar. Daí que, nessa interpretação, Morus narrasse isso como " cosa vista y hecha y experimentada" e não como mero sonho ou possibilidade. ${ }^{5}$

Nesse trecho Thomas Morus não é mencionado, mas a referência à Utopia é clara. De mais a mais, as próximas passagens dirimem qualquer dubiedade. Após se referir outra vez à inadequação dos nativos às leis europeias, reforçou a conveniência de "leyes, ordenanzas y costumbres que fuesen más conformes a las suyas, y a las de aquéllos de la edad dorada que tanto conforman con ellas" (Quiroga, 2002: 218). Essa observação resultou em novo comentário sobre a criação moreana:

Y por esto tengo para mí, por cierto, que sabido y entendido por el autor del muy buen estado de la república, ${ }^{6}$ de donde como de dechado se sacó el de mi parecer, varón ilustre y de genio más que humano, el arte y manera de las gentes simplicísimas de este Nuevo Mundo, y pareciéndole que en todo eran conformes y semejantes a aquéllas de aquella gente de oro de aquella primera edad dorada, sacó para el único remedio de él y de ellas, como inspirado del Espíritu

\footnotetext{
${ }^{2}$ A apresentação de Rafael Hitlodeu contém as seguintes palavras: "deixou aos irmãos os bens de família que tinha na sua pátria (é português) e na mira de lançar os olhos pelo orbe da terra, juntou-se a Américo Vespúcio e nas três últimas das suas quatro viagens, cujo relato constitui já objecto de leitura em diversas partes, foi seu companheiro inseparável, se excluirmos que, na última, não regressou com ele" (Morus, 2009: 232). Além disso, Morus estava familiarizado com outros textos sobre as viagens dos portugueses (Lestringant, 2006; Martins, 2009).

${ }^{3} 0$ segundo livro termina com essas palavras: "Entretanto, se não posso prestar assentimento a tudo o que foi dito, [...] também me é fácil confessar que muitíssimas coisas há na terra de Utopia que gostaria de ver implantadas nas nossas cidades, em toda a verdade e não apenas em expectativa." (Morus, 2009: 415).

${ }^{4}$ Cf. João 20,24-29.

${ }^{5}$ Em carta a Tomás Lupset, Guilherme Budé (in Morus, 2009: 197-206) aborda o relato de Rafael Hitlodeu como realidade histórica. Essa leitura, decerto metafórica, abre portas para a interpretação da obra como um projeto, à maneira como fez Vasco de Quiroga.

${ }^{6}$ Tradução da parte do título - de optimo reipublicae statu - que acabou por denominar a obra. Em português temos "A melhor forma de governo" (Morus, 2009).
} 
Santo, de las costumbres de aquéllas, las ordenanzas y muy bien estado de república en que se podrían guardar, conservar e industriar muy mejor y más fácilmente sin comparación que por otra manera alguna ni estado que se les pueda dar, que no les sea tan natural ni tan conforme a su arte, manera y condición ni tan bastante para hacerlos bastantes para no se consumir ni acabar, y para introducir la fe y policía mixta que solamente les falta; que lo demás parece que todo les sea propio y natural. Porque, aunque es así verdad, que sin la gracia y clemencia divina no se puede hacer ni edificar edificio que algo valga, pero mucho y no poco aprovecha y ayuda cuándo ésta cae y dora sobre buenos propios naturales que conforman con el edificio. (Quiroga, 2002: 218).

Aqui está explícito que Vasco de Quiroga partiu da Utopia para construir o seu projeto. A palavra dechado designa algo digno de ser imitado, que é exemplar, enfim, um modelo (Covarrubias Horozco, 1611: 637; "DLE", 2014; Brandão; Berliner, 2001: 387). Thomas Morus era, para ele, um homem ilustre e de gênio mais que humano, cujo exemplo valia a pena seguir. Não há referências à vida de Morus - executado em 6 de julho de 1535 (Nascimento, 2009: 172), quando a Información en derecho era escrita ${ }^{7}$-, sendo possível concluir que a opinião de Quiroga se originou das boas impressões causadas pela leitura da Utopia.

Quiroga não tinha dúvidas de que Morus conhecia e compreendia os costumes dos povos do Novo Mundo. 0 texto é rebuscado, escrito de forma indireta e, portanto, de difícil compreensão. Na ordem direta temos que "el arte y manera de las gentes" era "sabido y entendido por el autor". Parece uma inferência a partir do texto da Utopia, que, como visto acima, alude às Quatro Navegações de Américo Vespúcio (2003). 0 florentino não foi citado na Información, e assim, ao que tudo indica, essa conclusão de Quiroga resulta de sua própria interpretação do texto, e não de informações concretas sobre os dados possuídos pelo humanista inglês.

Senão, vejamos: a perfeita adequação das leis utópicas aos índios do Novo Mundo, na visão de Quiroga, tornava evidente que Morus compreendia bem a sua natureza. De outra forma, como explicar tal coincidência? Some-se a isso o entendimento de que a imagem da idade de ouro funcionava muito bem para explicar aos europeus como eram os índios. A tradução para o latim das Saturnais, feita por Morus, e a edição que circulava na Nova Espanha, que continha a Utopia e a obra de Luciano, permitiram então a Quiroga concluir que Morus compartilhava de sua chave explicativa: os índios eram semelhantes aos homens da idade de ouro, conforme a descrição do autor grego.

\footnotetext{
${ }^{7}$ A Información foi concluída em 24 de julho de 1535, apenas 18 dias após a morte de Morus. Enquanto o humanista inglês caminhava para a execução, era homenageado na Nova Espanha, numa trágica ironia.
} 
A Utopia seria então a descrição de uma república cuja forma de governo era adequada a essas gentes. Quiroga pretendeu conhecer as intenções por trás da redação da narrativa sobre a melhor forma de governar. Como um bom médico humanista, Morus teria preparado esse fármaco com a intenção de sanar o caos americano. Não era só uma boa solução, mas o único remédio acertado para o Novo Mundo e seus habitantes.

Agora há também um agente que não pode ser ignorado, o Espírito Santo. Morus não escreveria por si só, a partir de seu gênio criativo, mas inspirado pelo Espírito Santo. A palavra inspirado vem do grego $\theta \varepsilon o ́ \pi v \varepsilon v \sigma \tau o \varsigma$ (theopneustos), provavelmente composto a partir de

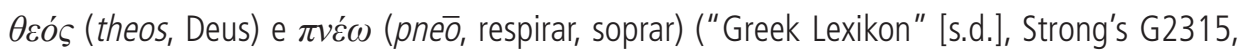
G2316 e G4154), podendo ser traduzida literalmente como soprado por Deus, no contexto do Novo Testamento. ${ }^{8}$ A ação é executada por Deus, sendo o ser humano o receptor da operação divina.

A tradução literal mencionada acima, baseada na etimologia, é insuficiente porque restringe o conceito de inspiração. No século XIX, círculos fundamentalistas dos Estados Unidos passaram a conceber "a Bíblia como sendo totalmente divina", como tendo sido "literalmente ditada ao escritor, e seu resultado estaria livre da contribuição humana". Por isso a forma correta de interpretá-la seria a literal, o que ainda encontra ecos atualmente. Essa é uma formulação bastante recente na história da interpretação bíblica, a exemplo da tendência liberal, ${ }^{9}$ surgida no século XVII e com apogeu no XIX, que trata a "Bíblia como algo total e exclusivamente humano" (Mendes e Santos, 2007: 540 e 545). À parte sua pobreza analítica, nenhuma das duas tem serventia aqui pelo simples fato de serem bastante recentes.

Uma terceira tendência "concebe o texto bíblico como produto da simultaneidade entre o divino e o humano", propondo "uma abordagem conjuntiva e não disjuntiva" (Mendes e Santos, 2007: 540). Mais recente que as outras duas, essa forma de interpretar recupera a tradição renascentista, que conferia à exegese um papel central na interpretação do texto bíblico sem descartar a intervenção divina em sua composição. ${ }^{10}$ Muitos humanistas participaram

\footnotetext{
${ }^{8}$ Convém lembrar que a relação entre o vento ou sopro com Deus já estava posta no primeiro relato da criação, em Gênesis 1,2, quando lemos que "um vento de Deus pairava sobre as águas" (A Bíblia de Jerusalém, 1985: 31) ou que "o espírito de Deus pairava sobre a face das águas" (Bíblia Hebraica, 2006: 11). A palavra hebraica traduzida como vento ou espírito é בוּ_ (ruwach), que a Septuaginta, versão grega do Antigo Testamento produzida em Alexandria entre os séculos III e I a. C., verteu como $\pi v \varepsilon \tilde{v} \mu \alpha \theta \varepsilon o \tilde{v}$ (pneuma theou, espírito de Deus) ("Hebrew Lexikon", [s.d.], Strong's H7307). A raiz de $\pi v \varepsilon \tilde{v} \mu \alpha$

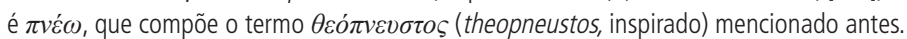

${ }^{9}$ Libera/tem aqui um sentido teológico, remetendo ao "racionalismo protestante do século XIX" (Mendes e Santos, 2007: 545).

10 "Como isso é possível? Jeremias fala, com toda a sua alma, e quem está falando é Deus; Paulo fala, com toda a sua paixão, e Deus é quem está falando. Algo misterioso tem de ocorrer em Paulo e em Jeremias para que, falando eles, Deus fale por meio deles." (Schökel, 1992: 35).
} 
desse debate, entre eles Erasmo e Morus, tendo surgido diversas obras que abordavam 0 assunto (Pires, 1996).

Nesse sentido, Luis Alonso Schökel (1992: 40) explicou a ideia de inspiração como análoga à encarnação:

o Espírito não cria do nada a matéria orgânica ou mineral que se irá transformando no corpo de Jesus; ele usa uma matéria animada preexistente, o corpo santificado de uma virgem. Também na inspiração o autor emprega materiais preexistentes: linguagem, motivos literários, procedimentos estilíisticos, citações etc. Não é necessário que esse material seja, por sua vez, obra do Espírito.

Assim, o Espírito Santo usaria as características dos indivíduos para transmitir sua mensagem, não havendo necessidade de suprimi-las para ditar suas palavras, como pensam os fundamentalistas. É significativo que Schökel (1992: 34 e 35) cite São João Crisóstomo em sua exposição, pois Vasco de Quiroga usou os textos desse santo para justificar e apoiar seus projetos na América. Essa ideia se harmoniza bem com o texto da Información: Morus teria sido movido pelo Espírito para escrever a Utopia, de forma sobrenatural e, simultaneamente, empregando seus conhecimentos históricos e linguísticos na composição do texto. Isso não fazia do inglês um santo, mas conferia legitimidade às suas palavras e, por derivação, à utopia quiroguiana.

Com isso é possível compreender melhor o texto: a inspiração do Espírito Santo se associava a Morus, "varón ilustre y de genio más que humano", com seus conhecimentos sobre os costumes dos índios para, através do autor, gerar um projeto perfeitamente adequado às necessidades do Novo Mundo, a fim de garantir o crescimento da igreja que ali nascia. 0 amálgama entre o divino e o humano era de absoluta necessidade, pois os homens, agindo por si próprios, produziriam apenas os frutos da carne, sendo guiados pela cupidez, como a curta história dos espanhóis na América bem demonstrava; por outro lado, para se comunicar com os seres humanos, Deus precisava descer ao seu nível de linguagem, ${ }^{11}$ e a melhor forma de fazer isso era por meio de seres humanos. É uma posição ambivalente, pois mostra otimismo com a intervenção divina e pessimismo com a atuação do homem no Mundo.

\footnotetext{
${ }^{11}$ Ao falar sobre a descida de Deus ao nível da linguagem humana para se tornar compreensível, Schökel (1992: 34) escreveu: "Essa descida de Deus foi denominada pelos padres gregos synkatabasis e traduzida pelos latinos como condescendentia. João Crisóstomo recorre a esse princípio quando encontra alguma fórmula bíblica que não pode ser tomada ao pé da letra; por exemplo, comentando Gn 3,8 - 'Deus passeava à brisa no entardecer' -, ele diz: 'Não menosprezemos o que é dito pela Sagrada Escritura, nem nos detenhamos na letra; consideremos que, por causa da nossa fraqueza, ela usa essa linguagem humilde para operar a nossa salvação de um modo digno de Deus; pois se quiséssemos tomar todas as palavras ao pé da letra, e não em sentido digno de Deus, não ocorreriam absurdos?'"
} 
Compreender a visão utópica de Quiroga exige atenção às seguintes palavras: " sin la gracia y clemencia divina no se puede hacer ni edificar edificio que algo valga". Além da inspiração do Espírito Santo na composição literária da Utopia, Deus precisava cooperar com os seres humanos na concretização do projeto. A fé de que havia intervenção divina no processo histórico reforçava a confiança num bom desfecho para a situação.

A Utopia, lida como projeto político-social, se adequaria perfeitamente à " arte, manera y condición" dos nativos, permitindo que sobrevivessem, garantindo-lhes as condições para se sustentarem, criando, com isso, as condições para que fossem evangelizados e que se implementasse uma boa política. Aliás, faltavam-lhes apenas a fé e a boa política, o resto já tinham. Essa conjuntura permitia sonhar com o sucesso da empresa, já que a ação de Deus só traria bons resultados se incidisse sobre boas pessoas, justamente o caso. ${ }^{12}$

Só então aparece no texto o nome de Thomas Morus:

Lo cual parece, porque este autor Tomás ${ }^{13}$ Moro fue gran griego y gran experto y de mucha autoridad, y tradujo algunas cosas de Luciano de griego en latín, donde, como dicho tengo, se ponen las leyes y ordenanzas y costumbres de aquella edad dorada y gentes simplicísimas y de oro de ella, según que parece y se colige por lo que en su república dice de estos, y Luciano de aquéllos en sus Saturniales, y debiérale parecer a este varón prudentísimo, y con mucha cautela y razón, que para tal gente, tal arte y estado de república convenía y era menester, y que en sola ella y no en otra se podía conservar por las razones todas que dichas son. (Quiroga, 2002: 218-219).

É a sequência imediata da citação anterior e tem o intuito de explicar e reforçar o ponto de vista exposto, como indicado pela expressão inicial "Lo cual parece". Morus é elogiado por seus grandes conhecimentos de grego, ${ }^{14}$ tido como um especialista, enfim, uma autoridade, ${ }^{15}$ daí que suas formulações merecessem tanto crédito. A combinação de inspiração divina, gênio e autoridade servia para ratificar o projeto quiroguiano.

0 texto é árduo e a interpretação, penosa. A dificuldade reside na alternância de referências a Luciano e Morus, mas os pronomes "estos" y "aquéllos" ajudam a desvendar o sentido. Leio assim: Luciano escreveu sobre "las leyes y ordenanzas y costumbres" da idade

\footnotetext{
${ }^{12} 0$ raciocínio traz à lembrança a parábola do semeador, em que a semente, a palavra do reino, só germina quando lançada sobre uma terra boa. Cf. Mateus 13,1-23.

${ }^{13}$ No manuscrito está grafado Thomas, mas a editora preferiu adotar a forma consolidada na língua espanhola.

${ }^{14}$ Morus foi um grande entusiasta da língua grega, defendeu a sua presença no currículo da universidade de Oxford e desenvolveu ferramentas para o seu estudo (Phélippeau, 2013).

${ }^{15}$ A palavra "autoridad" remete às escrituras sagradas, aos concílios, às tradições dos santos e aos doutores da igreja (Covarrubias Horozco, 1611: 249).
} 
de ouro nas Saturnais e se referiu a ela e aos seus habitantes (éstos), enquanto Morus "en su república" falava do Novo Mundo e suas gentes (aquéllos). A utopia de Quiroga conjuga os dois autores, vinculando antigos e modernos, bem ao gosto renascentista.

Morus, "varón prudentísimo", teria lido a obra de Luciano e associado os índios à idade de ouro - parece-me que tal entendimento influenciou a visão do próprio Quiroga sobre os nativos. A partir dessa intuição concluíra, " con mucha cautela y razón", que sua Utopia era apropriada a "tal gente", os índios. Mais do que isso, " tal arte y estado de república" seria a única saída para o bom governo do Novo Mundo. Como é possível notar, Quiroga projetou em Morus a sua interpretação da Utopia, pretendendo que o humanista inglês compartilhasse as suas próprias intenções.

Ao se aproximar da conclusão do trabalho, Quiroga passou a defender o seu projeto de objeções hipotéticas. A primeira a enfrentar foi "que policía humana en tanta perfección no se podría conservar, si todos no fuesen buenos, lo que parece imposible" (Quiroga, 2002: 223). A resposta remete ao casamento entre fé e política, a policía mixta de que tanto falou:

pues por ella se ordena y se ha de ordenar todo, así en lo temporal como en lo espiritual, por el apóstol de ella, que es su Majestad. Y así se provee por ella en lo uno, que no se olvida ni descuida en lo otro, antes quedando ordenado lo de la buena policía y conversaciones humanas, también quedan cortadas las raíces de toda discordia y desasosiego y de toda lujuria y codicia y ociosidad y pérdida de tiempo mal gastado, y se introduce la paz y justicia, y en ella se besan y abrazan con la equidad [...] (Quiroga, 2002: 223-224).

A monarquia espanhola, sendo católica, não podia separar a política da fé cristã. Estavam em voga naquela época as discussões sobre qual tipo de política era adequado às transformações recentes do mundo. Agnes Heller (1982: 256) escreveu sobre a solução proposta por Maquiavel: "visto que de facto já não existe uma ética comunitária do antigo tipo, seria absurdamente idealista, em política, confiar nesse tipo de ética como apoio. A política e a ética devem adaptar-se à nova situação". Vasco de Quiroga equacionava a questão de outro modo: pretendia reconstruir as condições sociais em que aquela ética comunitária floresceria.

A Utopia fornecia o modelo para isso. Apesar de os utopianos não professarem a religião cristã, Quiroga entendia que haviam tirado "proveito de práticas cristãs e da sabedoria a elas associada" para organizarem seu estado, conforme avaliou Guilherme Budé (in Morus, 2009: 202) em sua carta a Tomás Lipset, posta no início da Utopia à maneira de prefácio. Ordenando a sociedade de forma justa, equânime, as raízes dos males sociais que atribulavam a república seriam arrancadas. 
A carta de Budé (in Morus, 2009: 203) contém reflexões muito semelhantes às de Quiroga e, possivelmente, inspirara a sua perspectiva. A dívida com o Cristianismo seria evidenciada por "três preceitos divinos" seguidos na ilha de Utopia:

igualdade entre cidadãos ricos e pobres, ou, para quem preferir, cidadania completa em toda a sua escala; amor constante e firme de paz e harmonia; menosprezo de ouro e de prata. De mãos concertadas (como diz a expressão) aí se respeitam três antídotos (se assim posso dizer) de todas as fraudes, imposturas, rodeios, artimanhas, maquinações desonestas. Concedam os santos do céu, por quanto vale o seu nome, que estes três preceitos da legislação utopiana se fixem no espírito de todos os mortais com cavilhas de traves de convicção sólida e firme, e ver-se-iam imediatamente ruírem e esmorecerem a soberba, a cupidez, a contenda tresloucada e a quase totalidade das outras flechas vulníferas, que o adversário do Estígio atira, bem como compêndios de Direito, que, pela sua imensa força, retêm até à morte tantos espíritos exímios e sólidos, serem votados às traças como coisa sem conteúdo e inútil ou serem mandados para embrulho de merceeiro.

Dos três antídotos de Budé, Quiroga mencionou dois. 0 par "paz e harmonia", tradução do latim "pacis ac tranquilitatis", ${ }^{16}$ é semelhante a "paz y justicia", afinal a justiça traz tranquilidade. E "equidad" corresponde exatamente ao termo latino "aequalitatem" vertido para "igualdade". Quanto aos males, excetuando-se a dupla codicia - cupidez, não há equivalência exata. Apesar disso, não se pode dizer que "discordia y desasosiego y [...] lujuria [...] y ociosidad y pérdida de tiempo" distem muito das "fraudes, imposturas, rodeios, artimanhas, maquinações desonestas", da "soberba" e da "contenda tresloucada". ${ }^{17}$ As sensações causadas pela leitura desses dois trechos são muito parecidas, afinal eles têm o mesmo espírito.

Numa crítica sutil aos religiosos, Quiroga escreveu que os ministros de sua república estariam livres desses males. Trabalhariam para assegurar o alimento espiritual da população, de modo que "una ciudad de seis mil familias, y cada familia de diez hasta diez y seis casados familiares de ella, que son sobre sesenta mil vecinos, sea tan bien regida y gobernada en todo como si fuese sola una familia así en lo espiritual como en lo temporal" (Quiroga, 2002: 224). Ora, essa é uma referência clara à Utopia, onde se cuidava "para que nenhuma família (das seis mil que compõem cada cidade, sem incluir o seu aro) não tenha menos que dez nem mais

\footnotetext{
${ }^{16} 0$ texto latino da carta de Budé foi consultado a partir da edição bilíngue da Utopia (Morus, 1895: Ixxxvii), servindo para cotejar e verificar as palavras originais, quando necessário.

${ }^{17}$ Em latim: "fraudum, imposturarum, circunscriptionum, uersutiarum et planicarum improbitatum. [...] superbiam, contentionem uaesanam" (Morus, 1895: Ixxxvii-|xxxviii).
} 
que dezesseis púberes (quanto aos impúberes ninguém se permite definir o seu número)"18 (Morus, 2009: 310).

Essa citação livre mostra que Quiroga seguia de perto o texto moriano, propondo para as suas cidades o mesmo controle populacional da Utopia. Se essas estimativas fossem alcançadas, cada cidade teria no mínimo 60 e no máximo 96 mil habitantes, sem contar as crianças, o que corresponde à população das maiores cidades europeias no século XVI, conforme explicado por Aires A. Nascimento (in Morus, 2009: 310, nota 48). Mais do que fazer cálculos populacionais, Quiroga defendia que seriam necessários menos religiosos para a evangelização do Novo Mundo caso a sua policía mixta fosse implementada. Assim, "bastando pocos, poderse y han [de] hallar muy buenos y perfectos" (Quiroga, 2002: 224), ou seja, teriam como privilegiar a qualidade em vez da quantidade - outra crítica, dessa vez direcionada aos monges que atuavam como missionários na Nova Espanha. ${ }^{19}$

A organização social das cidades seguiria os seguintes termos:

Y, asimismo, de manera que cada familia tenga su padre y madre de familia a quien teman y acaten y obedezcan los de cada familia a los suyos, y que sean tales de quien reciban ejemplo y castigo y doctrina, y den cuenta cada cual de su familia y familiares de ella que estén a su cargo, y otros que han de ser como jurados de treinta en treinta familias, que han de ser a cargo de cada uno de estos jurados, a quien todos los de su juradería y parroquia obedezcan y acaten, y con quien se junten a proveer en todo lo necesario; sobre los cuales presidan y han de presidir los regidores, de cuatro en cuatro jurados, que han de ser a cargo de cada uno de los dichos regidores; demás de estos, ha de haber dos alcaldes ordinarios y un tacatecle; todos los susodichos indios elegidos por la orden que más largamente pone el parecer de la república, que no será de los peores, sino la mejor de las mejores que yo he visto; y, sobre todos, un alcalde mayor o corregidor español puesto por su Majestad y esta Real Audiencia en su nombre, y, para lo supremo, esta Real Audiencia en lo temporal ( Quiroga, 2002: 224).

É uma hierarquia em seis níveis, com a Audiência no topo, última instância nas questões temporais. Ela apontaria um alcalde mayor para os povoados, autoridade que conjugava funções administrativas e jurídicas, a exemplo da Audiência. Apenas espanhóis ocupariam esses níveis superiores, ao passo que os quatro níveis inferiores seriam ocupados exclusivamente por índios. A indicação através de eleição é importante, pois indica a adaptação

\footnotetext{
${ }^{18}$ Em latim: " ne ulla familia, quarum millia sex quaeque ciuitas, excepto conuentu, complectitur, pauciores quam decem, pluresue quam sexdecim puberes habeat. Impuberum enim nullus praefiniri numerus potest" (Morus, 1895: 154).

${ }^{19}$ Quiroga teve conflitos com os missionários que atuavam na Nova Espanha e solicitou a vinda dos jesuítas para a sua diocese, o que só aconteceu depois de sua morte (Serrano Gassent, 2001).
} 
do pensamento de Quiroga à realidade vivenciada. Antes, na Información, ele condenara a democracia.

Para efeito de comparação, recorro ao texto da Utopia:

Cada trinta famílias elege, todos os anos, um representante que designam na sua primitiva língua por sifogranto, e em língua mais recente filarco. A cada dez sifograntos, com as suas famílias, preside um traníboro na lingua de antigamente, hoje protofilarco. Finalmente, todos os sifograntos, que são duzentos, depois de jurarem que escolherão aquele que considerem mais útil, em votos secretos elegem como príncipe um entre quatro que o povo tiver designado.

De facto, cada um dos quatro bairros da cidade escolhe um representante para fazer parte do Senado. 0 cargo de príncipe é vitalício, e não pode ser destituído senão em caso de haver suspeita de propender para a tirania. Os traníboros ficam sujeitos a eleição anual, mas não são substituídos senão por motivo sério. Os restantes magistrados são todos anuais (Morus, 2009: 300).

A transposição é evidente, o que o diagrama abaixo ajuda a visualizar.

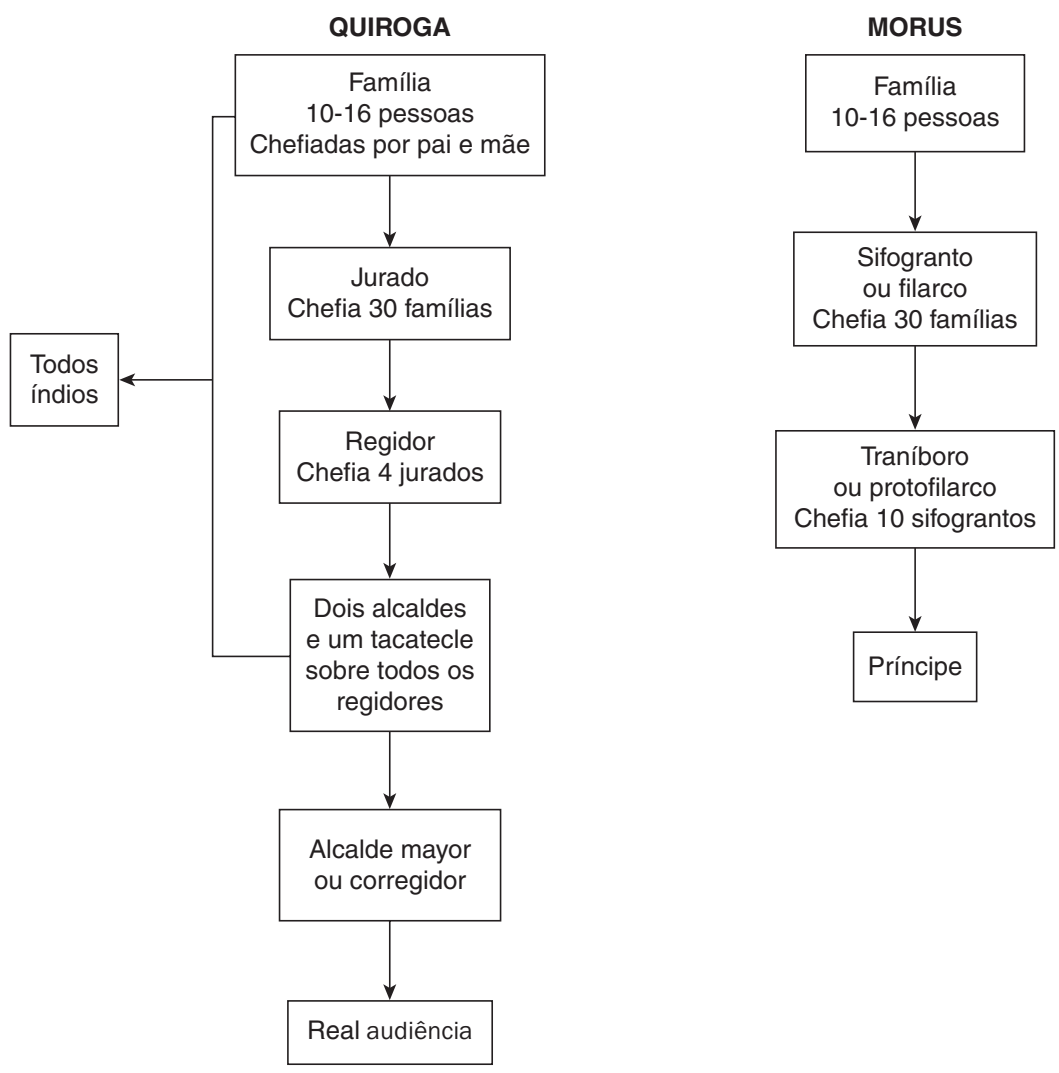


Apoiando-se em São João Crisóstomo, Santo Ambrósio, Ludolfo da Saxônia (o Cartuxo, 1295-1377), numa obra chamada Espejo de religiosos e em São Paulo, Quiroga defendeu que todos os cristãos deveriam vivenciar as virtudes cristãs, não apenas alguns santos ou devotos dedicados especialmente a isso. ${ }^{20}$ Dessa forma, a Utopia de Morus seria aplicável e seu projeto encontrava justificativa. Os ensinos evangélicos deviam ser seguidos por toda a cristandade.

O final da Información deixa claro que as respostas de Quiroga provinham da Utopia. Ali ele suplica que "se vea el preámbulo y razonamiento que al fin de ésta envio", no qual as dúvidas podiam ser esclarecidas. Esse preâmbulo era:

harto sabio y sutil, y aun a mi ver no menos verdadero, si no me engaño, y por asaz elegante estilo, a lo menos en el latín, donde yo a la letra lo saqué y traduje para este fin y efecto, y porque a todos fuese más familiar y no se les defendiese algún rato, como hizo a mí algo con todo quitado, aunque no de la sustancia e intento de la sentencia, para mejor aplicarlo a mi propósito (Quiroga, 2002: 234).

A sutileza e a sabedoria da obra são destacadas, mas também seu estilo elegante. A atenção ao estilo mostra uma posição próxima à de Erasmo na defesa da associação entre verdade e eloquência (cf. Sartorelli \& Leme, 2099). A preocupação com a tradução para o vernáculo, garantindo maior difusão, também o vincula aos círculos reformistas espanhóis, que verteram muitas obras para o castelhano, permitindo a sua popularização, e também traduziram partes das escrituras, até que isso fosse vetado pelo Concílio de Trento (cf. Bataillon, 1966: 494 ss.). Como muitas traduções da época, essa se realizou de forma mais livre, conforme 0 que hoje chamamos de adaptação, para superar as dificuldades impostas pelo texto e melhor se adequar ao propósito de Quiroga.

0 que efetivamente foi traduzido? 0 texto nos diz:

por el mismo Tomás Morus, ${ }^{21}$ autor de aqueste muy bien estado de república, en este preámbulo y razonamiento que sobre ella hizo como en manera de diálogo, donde su intención parece que haya sido proponer, alegar, fundar y probar por razones las causas por que sentía por muy fácil, útil, probable y necesaria la tal república entre una gente tal que fuese de la cualidad de

\footnotetext{
${ }^{20}$ Marcel Bataillon (1966: 44 ss.) expôs com muita clareza a história da popularização dos manuais espirituais na Espanha do início do século XVI. Esses manuais, dentre os quais se destacou a Vita Christi, do Cartuxo, permitiram ao povo comum desenvolver uma espiritualidade próxima da philosophia Christi que Erasmo defendeu, criando um ambiente propício para a reforma da Cristandade, pelo menos até a eclosão da reforma de Lutero e a repressão inquisitorial e contrarreformista.

${ }^{21} 0$ manuscrito não segue um padrão para nomear o humanista inglês: às vezes grafa Moro, noutras Morus.
} 
aquesta natural deste 22 Nuevo Mundo, que en hecho de verdad es casi en todo y por todo como él allí sin haberlo visto lo pone, pinta y describe, en tanta manera que me hace muchas veces admirar (Quiroga, 2002: 234).

Silvio Zavala (2007: 161-165, "Vasco de Quiroga, traducteur de L'Utopia") entendeu que Quiroga traduziu apenas o primeiro livro, que está em forma de diálogo, como mencionado na Información. Como a tradução desse "preámbulo y razonamiento" não é conhecida até hoje, é impossível confirmar a hipótese de Zavala. A sequência do texto, porém, abre outra possibilidade.

A interpretação apresentada é surpreendente porque, como já visto, enxerga nas intenções de Morus o desejo de provar que sua Utopia seria realizável no Novo Mundo. Lendo a obra hoje, é improvável julgá-la do mesmo jeito. Se já é difícil ver no primeiro livro esse arrazoado, é certo que ali Morus não "pone, pinta y describe" os naturais da América, pois as descrições dos utopianos estão na segunda parte. Por isso, suponho que Quiroga traduziu e adaptou o libelus aureus por inteiro, citou sua composição na Información en derecho e a usou para compor as Reglas y Ordenanzas 23 para os hospitais. Nesse caso o livro I seria o "preámbulo" e o livro II o "razonamiento", o que só poderá ser assegurado se a tradução for encontrada.

Por fim, Quiroga (2002: 234) sintetizou:

Porque me parece que fue como por revelación del Espíritu Santo, para la orden que convendría y sería necesario que se diese en esta Nueva España y Nuevo Mundo, según parece como que se le revelaron toda la disposición, sitio y manera y condición y secretos de esta tierra y naturales de ella; y también para responder y satisfacer a todos los contrarios y tácitas objeciones que sintió este varón prudentísimo que le se podrían oponer en su república, que son las mismas que se le han opuesto y podrán oponer a la de mi parecer [...].

Sendo uma espécie de resumo, quase todos os pontos aqui mencionados foram analisados acima. Resta tratar da ideia de revelação divina. Como Morus não vira o Novo Mundo, apenas por meio de uma revelação Ihe fora possível descrever seus habitantes e propor-lhes com tanto acerto um sistema de governo adequado a sua disposição, assim declarou Quiroga. Revelação não é o mesmo que inspiração: nesta o ser humano não precisa estar consciente do que se passa, enquanto naquela a coisa ou pessoa revelada é bem definida.

\footnotetext{
${ }^{22}$ Na edição de Serrano Gassent está "desde", o que não faz sentido. Verificando o manuscrito percebe-se que o correto é "deste".

${ }^{23}$ Reglas y Ordenanzas para el Gobierno de los Hospitales de Santa Fe de Mexico y Michoacán, Dispuestas por su Fundador el Rmo. Y Venerable Sr. Don Vasco de Quiroga, Primer Obispo de Michoacán (Quiroga, 2002: 251-274).
} 
"Toda revelação de Deus voltada para o exterior é reflexo da manifestação interna de Deus", ensina Schökel (1992: 22), seguindo as especulações de Santo Agostinho. Assim, para atender aos seus desígnios misteriosos, Deus dera ao conhecimento de Morus informações específicas para que, inspirado pelo Espírito Santo, ele escrevesse sua obra, da qual Quiroga tirara tanto proveito. ${ }^{24}$ Vai muito além do meu propósito adentrar a senda das elucubrações teológicas, mas cito isso porque penso que as palavras inspiración e suas derivadas não foram usadas meramente como sinônimos de revelación, ainda mais porque os humanistas tinham muito cuidado com o emprego dos termos. Como a Utopia e o Elogio da loucura demonstram, Erasmo e Morus adoravam jogar com os adjetivos, substantivos e verbos, dando grande atenção para a etimologia. Quiroga, influenciado pelos dois, não gastaria seu vocabulário aleatoriamente.

Essa síntese termina com uma citação das últimas linhas da carta de Guilheme Budé (in Morus, 2009: 206), para quem o relato sobre a Utopia era como um "alforbe de empreendimentos belos e úteis onde cada um pode ir buscar de empréstimo comportamentos transferíveis e adaptáveis à sua cidade". Vasco de Quiroga se aferrou a tais palavras e fez exatamente isso: transferiu e adaptou as ideias de Morus para a Nova Espanha, onde sonhou com um mundo novo e tentou realizá-lo.

Na Utopia, Thomas Morus fez uma crítica mordaz à sociedade inglesa do início do século XVI e descreveu uma ilha imaginária em que esses problemas estavam solucionados. Trata-se de uma formalização da experiência histórica, decerto bastante dúbia, pois carregada de ironias e jogos de palavras desde o título, que pode ser entendido como não-lugar ou como bom-lugar. A intenção crítica da obra é inquestionável, mas a sua leitura como projeto político-social é no mínimo ambígua. 0 próprio autor plantou essa dúvida ao dizer que não podia "prestar assentimento a tudo o que foi dito" para, em seguida, assegurar que "muitíssimas coisas há na terra de Utopia que gostaria de ver implantadas nas nossas cidades" (Morus, 2009: 415).

Se a tradição interpretativa manteve essa dúvida, não se pode dizer o mesmo de Vasco de Quiroga. Ele considerava a descrição da Utopia tão viável que dedicou 35 anos de sua vida para efetivá-la nos dois pueblos-hospitales de Santa Fé. Essa leitura, feita no alvorecer da modernidade, ficou por muito tempo excluída das histórias das utopias talvez porque destoe da ideia comumente aceita de que a Utopia e o gênero literário dela derivado só passaram a

\footnotetext{
${ }^{24}$ Schökel distingue três caminhos de revelação: pela criação, pela história e pela palavra. A partir dessa tríade, pode-se pensar que o Novo Mundo fora revelado pela história através das grandes viagens empreendidas pelos reis católicos; pela palavra através dos testemunhos escritos sobre ele, como as cartas de Vespúcio; e pela criação, na natureza dos índios, tão inclinada para o bem.
} 
ser tratados como projeto político-social a partir do final do século XVIII, notadamente com os empreendimentos do Conde de Saint-Simon, de Charles Fourier e Robert Owen.

Ademais, a Información en derecho elucida as relações entre história e literatura. Enquanto Morus partiu da experiência história para criar o texto literário, Quiroga fez o caminho inverso, tomando a Utopia como modelo e aplicando-o à vida cotidiana. É claro que as relações entre história e literatura não são tão simples: o próprio Quiroga enxergou a necessidade de adaptar o que lera aos hábitos dos índios de México e de Michoacán, elaborando uma releitura da obra de Morus que ficou registrada nas Reglas y ordenanzas que redigiu no fim da sua vida para normatizar o governo dos povoados.

É impossível, dentro dos limites deste artigo, discutir profundamente a historicidade do conceito de literatura. No entanto, conforme apontou João Adolfo Hansen (2007: 254), a definição atual de literatura não existia no século XVI, quando os "códigos linguísticos são, basicamente, códigos retórico-poéticos e teológico-políticos". Portanto, não devemos transpor a nossa conceituação para o século XVI e tratar acriticamente Utopia como literatura.

Deve estar claro, porém, que Utopia foi entendida, "desde o início, como meta-geográfica e meta-histórica" (Firpo, 2005: 230), um relato de viagem imaginário mas verossímil. Raymond Trousson se preocupou com o alargamento e a dispersão do significado da palavra "utopia" ao longo dos séculos e, por isso, retomou a distinção entre ela e o "utopismo". A partir disso, enfatizou que "a utopia se caracteriza, certamente, por um conteúdo e por um projeto, mas, enquanto gênero literário, ela supõe igualmente exigências de formulação de sua mensagem, requer o estudo de critérios estruturais, diegéticos e estilísticos" (Trousson, 2005: 128).

A delimitação de um gênero literário só ocorre após o surgimento de uma série de obras semelhantes que possam ser analisadas em conjunto. Jorge Bastos da Silva (2009: 168) argumentou que "no primeiro quartel de Quinhentos não existia um dispositivo de convenções genéricas pelo qual pudesse ser reconhecido o tipo de obra literária constituído pela Utopia de More, ainda que os leitores instruídos identificassem prontamente outros tipos de realizações literárias". ${ }^{25}$ É um texto ambivalente, aberto, com várias interpretações possíveis. Como a Utopia é a obra inaugural do gênero utópico, sua classificação, é claro, foi feita a posteriori, e é impossível decidir se Morus pretendia ou não criar tal gênero.

A despeito das intenções de Morus, a forma básica da Utopia foi logo imitada por muitos autores e embasou diversos relatos que seguiam a mesma estrutura: alguém viaja para um

\footnotetext{
${ }^{25}$ Entre esses tipos Silva (2009: 168) menciona "a tragédia, a comédia, a epopeia, o soneto, a elegia, o epigrama, 0 auto de moralidade, a mascarada, o imaginário pastoril com suas variantes".
} 
lugar distante e desconhecido, e retorna para narrar os seus sucessos. A descrição desse lugar opera sempre uma inversão da experiência histórica compartilhada entre o narrador e seus ouvintes - as utopias resolvem os problemas da sociedade que as originou. 0 conjunto dessas obras foi percebido posteriormente como um gênero literário, cujos exemplos mais conhecidos são a Cidade do Sol, de Thommaso Campanella, e a Nova Atlântida, de Francis Bacon, que, com a obra de Morus, formam a tríade das utopias clássicas.

Como seguiam a forma do relato imaginário, a Utopia e as demais obras do gênero utópico foram concebidas e lidas como ficções. ${ }^{26}$ Cada uma estava sempre vinculada ao seu período histórico, criticando-o e apresentando algum tipo de solução para seus problemas. Ora, o conceito atual de literatura aparece comumente vinculado à ideia de ficção (Wood, 2012). Se aceitarmos isso, podemos, para efeitos de análise, tratar a Utopia e o gênero utópico como literatura, mesmo reconhecendo que tal caracterização não existia no século XVI. Esse foi o procedimento adotado.

Conforme Hansen (2007: 266), a literatura pressupõe "a iniciativa autoral individualizada e a autonomia crítica de seus produtores" e prescreve "apropriação e crítica estética", além de prever "a contemplação desinteressada de seus públicos". A partir do que se sabe sobre o processo de criação da Utopia, parece-me possível enquadrá-la nesses critérios. Todavia, nem sempre a leitura das obras literárias é meramente contemplativa ou desinteressada, e a interpretação de Quiroga atesta isso de forma clara.

Enfim, a obra de Vasco de Quiroga explicita a complexidade das relações entre história e literatura. Por um lado, fica claro que a literatura sempre está vinculada à história, pois a composição do texto literário deve muito à experiência de vida do autor. Carregada de historicidade, pode se converter em fonte para os estudos históricos. Por outro lado, a literatura tem a capacidade de interferir na história, na medida em que inspire ações de homens e mulheres comprometidos com a transformação da sociedade e dispostos a investir seus esforços nesse propósito. Quiroga foi um desses homens, e seu legado ainda ecoa na memória dos Purépecha de Michoacán e além, entre aqueles que sonham com um mundo mais justo e menos desigual.

\section{REFERÊNCIAS BIBLIOGRÁFICAS}

A Bíblia de Jerusalém. São Paulo: Paulinas, 1985.

BATAILLON, M. Erasmo y España: estudios sobre la historia espiritual del siglo XVI. 2aㅡ. ed. México: Fondo de Cultura Económica, 1966.

\footnotetext{
${ }^{26}$ Hansen (2007: 255) reconhece que havia "regimes discursivos ficcionais e não-ficcionais" naquele período.
} 
BRANDÃO, E. \& BERLINER, C. (trads.). SEÑAS: Diccionario para la enseñanza de la lengua española para brasileños. 2a ed. São Paulo: Martins Fontes, 2001.

COVARRUBIAS HOROZCO, S. de. Tesoro de la lengua castellana o española. En Madrid: por Luis Sanchez, 1611. Disponível em: <http://fondosdigitales.us.es/fondos/libros/765/16/tesoro-de-la-lengua-castellana-o-espanola/>. Acesso em: 17 ago. 2015.

Diccionario de la lengua española. Disponível em: <http://dle.rae.es/>. Acesso em: 18 ago. 2015.

FIRPO, L. Para uma definição da "utopia". Morus - Utopia e Renascimento, n. 2: 227-237, 2005.

GORODOVITS, D. \& FRIDLIN, J. (trads.). Bíblia Hebraica. São Paulo: Sêfer, 2006.

Greek Lexikon. Disponível em: <https://www.blueletterbible.org/lang/lexicon/lexicon.cfm>. Acesso em: 13 set. 2015.

GREEN, O. H. España y la tradición occidental: el espiritu castellano en la literatura desde "El Cid" hasta Calderón. Madri: Editorial Gredos, 1969.

GUEVARA, A. de. Menosprecio de corte y alabanza de aldea. [s.l: s.n.], 1539. Disponível em: <http://www. filosofia.org/cla/gue/gueca.htm>. Acesso em: 26 dez. 2015.

HANSEN, J. A. Para uma história dos conceitos das letras coloniais luso-brasileiras dos séculos XVI, XVII e XVIII. In: FERES JÚNIOR, J. \& JASMIN, M. (orgs.). História dos conceitos: diálogos transatlânticos. Rio de Janeiro: PUC-Rio/ Loyola/ IUPERJ, 2007. p. 253-266.

Hebrew Lexikon. Disponivel em: <http://www.blueletterbible.orghttps://www.blueletterbible.org/lang/lexicon/lexicon.cfm>. Acesso em: 27 dez. 2015.

HELLER, A. O homem do Renascimento. Lisboa: Presença, 1982.

LESTRINGANT, F. 0 impacto das descobertas geográficas na concepção política e social da utopia. Morus Utopia e Renascimento, n. 3: 155-173, 2006. Disponível em: <http://revistamorus.com.br/index.php/morus/ article/view/19>. Acesso em: 17 ago. 2015.

MARTINS, J. V. de P. Thomas More e a Utopia. In: Utopia ou a melhor forma de governo. 2a ed. Lisboa: Fundação Calouste Gulbenkian, 2009. p. 23-139.

MENDES, J. T. \& SANTOS, E. da S. Considerações sobre inspiração bíblica. Teocomunicação, v. 37, n. 158: 537551, 2007. Disponivel em: <http://revistaseletronicas.pucrs.br/teo/ojs/index.php/teo/article/view/2733>. Acesso em: 27 dez. 2015.

MORUS, T. Utopia. Londres: Oxford, Clarendon Press, 1895. Disponível em: <http://archive.org/details/theutopiaofsirth00moreuoft>. Acesso em: 19 dez. 2015.

Utopia ou a melhor forma de governo. 2ª ed. Lisboa: Fundação Calouste Gulbenkian, 2009.

NASCIMENTO, A. A. Prolegómenos à leitura da Utopia Moriana. In: Utopia ou a melhor forma de governo. 2a ed. Lisboa: Fundação Calouste Gulbenkian, 2009: 145-192.

PHÉLIPPEAU, M.-C. Thomas Morus e a abertura humanista. Morus - Utopia e Renascimento, n. 9: 157-175, 2013. Disponível em: <http://www.revistamorus.com.br/index.php/morus/article/view/217>. Acesso em: 28 dez. 2015. 
PIRES, M. J. Teologia e o poder da palavra: o desafio renascentista. Revista da Faculdade de Letras: Línguas e Literaturas, n. 13: 41-50, 1996. Disponível em: <http://hdl.handle.net/10216/7720>. Aceso em: 27 dez. 2015.

QUIROGA, V. de. Información en derecho. [Manuscrito]. México. 24 jul. 1535. Disponível em: <http://bdh.bne. es/bnesearch/detalle/bdh0000145296>. Acesso em: 18 dez. 2015.

. La utopía en América. Edição de Paz Serrano Gassent. Madri: Dastin, 2002.

SARTORELLI, E. C. \& LEME, F. G. Erasmo, barbari, indocte docti e ciceroniani: os modelos clássicos e o ensinamento cristão. Letras Clássicas, n. 13: 3-28, 19 dez. 2009. Disponível em: <http://www.revistas.usp.br/ letrasclassicas/article/view/73920 >. Acesso em: 22 dez. 2015.

SCHÖKEL, L. A. A palavra inspirada: a Bíblia à luz da ciência da linguagem. Trad. Maria Stela Gonçalves. São Paulo: Edições Loyola, 1992.

SERRANO GASSENT. Vasco de Quiroga: utopía y derecho en la conquista de América. Madri: Fondo de Cultura Económica de España; Universidad Nacional de Educación a Distancia, 2001.

SILVA, J. B. da. Thomas More, utopista malgré lui. Morus - Utopia e Renascimento, n. 9: 167-172, 2009. Disponível em: <http://revistamorus.com.br/index.php/morus/article/view/75>. Acesso em: 23 jul. 2017.

TROUSSON, R. Utopia e utopismo. Morus - Utopia e Renascimento, n. 2: 123-135, 2005.

VESPUCCI, A. Novo Mundo: as cartas que batizaram a América. São Paulo: Editora Planeta do Brasil, 2003.

WARREN, F. B. Vasco de Quiroga and his pueblo-hospitals of Santa Fe. Washington, DC: Academy of American Franciscan History, 1963.

WITEZE JUNIOR, G. A Carta ao Conselho de Índias, de Vasco de Quiroga. Versão bilíngue. Morus - Utopia e Renascimento, v. 11, n. 1: 111-130, 2016. Disponível em: <http://www.revistamorus.com.br/index.php/ morus/article/view/275>. Acesso em: 5 fev. 2017.

WOOD, J. Como funciona a ficção. Trad. Denise Bottmann. São Paulo: Cosac Naify, 2012.

ZAVALA, S. A. Recuerdo de Vasco de Quiroga. México: Editorial Porrúa, 2007. 